University of Nebraska - Lincoln

DigitalCommons@University of Nebraska - Lincoln

Public Health Resources

Public Health Resources

2008

\title{
An in vitro Method of Alcoholic Liver Injury Using Precision-Cut Liver Slices From Rats
}

Lynell W. Klassen

Experimental Immunology Laboratory at the University of Nebraska Medical Center, Department of Internal Medicine, Section of Rheumatology, 983025 Nebraska Medical Center, Omaha, NE 68198-3025, United States

Geoffrey M. Thiele

Experimental Immunology Laboratory at the University of Nebraska Medical Center, Department of Internal Medicine, Section of Rheumatology, 983025 Nebraska Medical Center, Omaha, NE 68198-3025, United States

Michael J. Duryee

Experimental Immunology Laboratory at the University of Nebraska Medical Center, Department of Internal Medicine, Section of Rheumatology, 983025 Nebraska Medical Center, Omaha, NE 68198-3025, United States

Courtney S. Schaffert

Experimental Immunology Laboratory at the Omaha Veterans Administration Medical Center, Research Services 151, 4101 Woolworth Avenue, Omaha, NE 68105, United States

Amy L. DeVeney

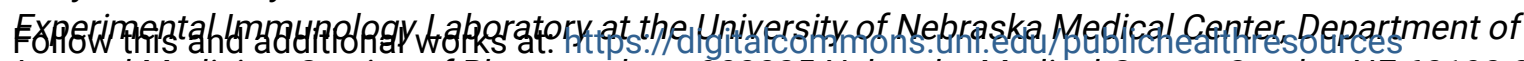
Internal Medicine, Section of Rheumatology, 983025 Nebraska Medical Center, Omaha, NE 68198-3025, C.ifearsedtthe Public Health Commons

See next page for additional authors

Klassen, Lynell W.; Thiele, Geoffrey M.; Duryee, Michael J.; Schaffert, Courtney S.; DeVeney, Amy L.; Hunter, Carlos D.; Olinga, Peter; and Tuma, Dean J., "An in vitro Method of Alcoholic Liver Injury Using PrecisionCut Liver Slices From Rats" (2008). Public Health Resources. 34.

https://digitalcommons.unl.edu/publichealthresources/34

This Article is brought to you for free and open access by the Public Health Resources at DigitalCommons@University of Nebraska - Lincoln. It has been accepted for inclusion in Public Health Resources by an authorized administrator of DigitalCommons@University of Nebraska - Lincoln. 
Authors

Lynell W. Klassen, Geoffrey M. Thiele, Michael J. Duryee, Courtney S. Schaffert, Amy L. DeVeney, Carlos D. Hunter, Peter Olinga, and Dean J. Tuma 


\title{
An in vitro method of alcoholic liver injury using

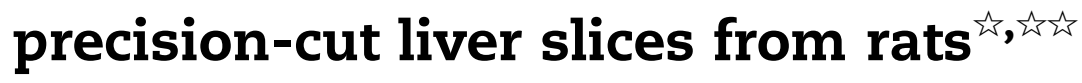

\author{
Lynell W. Klassen $^{a, b}$, Geoffrey M. Thiele $e^{a, b, d}$, Michael J. Duryee ${ }^{a, b, *}$, Courtney S. Schaffert ${ }^{b, c}$, \\ Amy L. DeVeney ${ }^{a, b}$, Carlos D. Hunter ${ }^{a, b}$, Peter Olinga ${ }^{e}$, Dean J. Tuma ${ }^{b, c}$
}

a Experimental Immunology Laboratory at the University of Nebraska Medical Center, Department of Internal Medicine, Section of Rheumatology, 983025 Nebraska Medical Center, Omaha, NE 68198-3025, United States

${ }^{\mathrm{b}}$ Experimental Immunology Laboratory at the Omaha Veterans Administration Medical Center, Research Services 151, 4101 Woolworth Avenue, Omaha, NE 68105, United States

${ }^{\mathrm{c}}$ Department of Internal Medicine, Section of Gastroenterology and Hepatology, 982000 Nebraska Medical Center, Omaha, NE 68198-2000, United States

d University of Nebraska Medical Center, Department of Pathology and Microbiology, 986495 Nebraska Medical Center, Omaha, NE 68198-6495, United States

e University of Groningen, GUIDE, Department of Pharmacokinetics \& Drug Delivery, Ant.Deusinglaan 1, 9713 AV Groningen, The Netherlands

\section{A R T I C L E I N F O}

Article history:

Received 25 February 2008

Accepted 8 May 2008

Keywords:

Precision-cut liver slice

Alcoholic liver disease

Fatty liver

Acetaldehyde

Ethanol metabolism

\begin{abstract}
A B S T R A C T
Alcohol abuse results in liver injury, but investigations into the mechanism(s) for this injury have been hampered by the lack of appropriate in vitro culture models in which to conduct in depth and specific studies. In order to overcome these shortcomings, we have developed the use of precision-cut liver slices (PCLS) as an in vitro culture model in which to investigate how ethanol causes alcohol-induced liver injury. In these studies, it was shown that the PCLS retained excellent viability as determined by lactate dehydrogenase and adenosine triphosphate (ATP) levels over a $96-\mathrm{h}$ period of incubation. More importantly, the major enzymes of ethanol detoxification; alcohol dehydrogenase, aldehyde dehydrogenase, and cytochrome P4502E1, remained active and PCLS readily metabolized ethanol and produced acetaldehyde. Within $24 \mathrm{~h}$ and continuing up to $96 \mathrm{~h}$ the PCLS developed fatty livers and demonstrated an increase in the redox state. These PCLS secreted albumin, and albumin secretion was decreased by ethanol treatment. All of these impairments were reversed following the addition of 4-methylpyrazole, which is an inhibitor of ethanol metabolism. Therefore, this model system appears to mimic the ethanol-induced changes in the liver that have been previously reported in human and animal studies, and may be a useful model for the study of alcoholic liver disease.
\end{abstract}

\footnotetext{
Supported by: National Institutes of Health Grants R01 AA10435, R37 AA07818, and R21 AA15505-01A2. Also supported by the Department of Veterans Affairs National Merit Review Program and the Department of Internal Medicine at the UNMC.

All work was performed in the Experimental Immunology Laboratory at the Omaha Veterans Administration Medical Center, Research Services 151, 4101 Woolworth Avenue, Omaha, NE 68105.

* Corresponding author at: Omaha Veterans Administration Medical Center, 4101 Woolworth Avenue, Omaha, NE 68105, United States. Tel.: +1 402995 3550; fax: +1 4024490604 .

E-mail address: mduryee@unmc.edu (M.J. Duryee).

Abbreviations: ATP, adenosine triphosphate; LDH, lactate dehydrogenase; 4-MP, 4-methylpyrazole; AA, acetaldehyde; ALD, alcohol liver disease; ADH, alcohol dehydrogenase; ALDH, aldehyde dehydrogenase; CYP2E1, cytochrome P450 2E1; PCLS, precision-cut liver slices.
} 
1.

\section{Introduction}

Alcohol abuse causes abnormalities in liver structure and function, including fatty liver, apoptosis, necrosis, fibrosis, and cirrhosis [1,2]. Despite numerous studies over the years, the mechanisms of alcohol hepatotoxcity remain unclear. Traditionally, ethanol-feeding animal models have been used to study the physiological responses in the liver. Although studies with this model have provided a wealth of information, detailed mechanistic studies are problematic using this in vivo model. Therefore, several in vitro culture systems have been developed in order to determine the effects of ethanol administration on the liver. These systems include primary hepatocyte cultures [3,4], HepG2 hepatoma cells expressing stable exogenous alcohol dehydrogenase $[5,6]$ or cytochrome P4502E1 [7], and WIF-B cells [8,9]. Although these models have provided valuable information, numerous limitations and weaknesses are evident in these systems. For example, differentiated functions are rapidly lost, cell-cell and cellmatrix interactions are compromised, and most importantly other cell types in the liver besides heptatocytes are not present.

In view of the limitations of the currently established in vitro culture systems for mechanistic studies of ethanol hepatotoxicity, precision-cut liver slices (PCLS) were chosen in this study as a possible model of alcoholic liver disease. PCLS have been used previously for a variety of metabolic and toxicological studies [10-13], and appear to be applicable for ethanol hepatotoxicity studies. In this model, normal lobular hepatic architecture is maintained, and the cell-cell and cellmatrix interactions mimic the in vivo situation. In addition and most importantly, PCLS contain hepatocytes and the other non-parenchymal cells of the liver, namely Kupffer cells, endothelial cells, and stellate cells. Since these other cell types likely contribute to the deleterious effects of ethanol [2], it would appear that PCLS could be a valuable model to further delineate the mechanism(s) of ethanolinduced liver injury.

The purpose of this study was to validate the use of PCLS as a model to investigate ethanol hepatotoxcity. Ethanol metabolism and steady state levels of acetaldehyde were determined in this model. In addition, the ability to reproduce some of the known effects of ethanol on the liver; such as, formation of a fatty liver, altered hepatic redox state, and impaired albumin secretion, were investigated.

\section{Materials and methods}

\subsection{Rats}

Male Wistar rats were purchased from Charles River Laboratories (Willmington, MA) and maintained on a Purina rat chow diet. All animals were allowed free access to their food and/or water up to $1 \mathrm{~h}$ prior to sacrifice. All procedures were approved by the Animal Subcommittee of the Omaha VA Medical Center, and are in accordance with the National Institutes of Health Guidelines on the Use of Laboratory Animals.

\subsection{Rat precision-cut liver slices}

Rats weighing 200-300 g were anesthetized using Isoflurane. The basic method of Olinga et al. [14] was used to prepare the PCLS. Briefly, the abdominal cavity was scrubbed with betadine and entered exposing the liver. The inferior vena cava was clipped, blood allowed to drain for $1 \mathrm{~min}$, the liver excised and quickly placed into oxygenated V-7 cold preservation buffer purchased from Vitron Inc. (Tucson, AZ). Multiple $(8 \mathrm{~mm})$ cylindrical tissue cores were cut using a hand held coring tool, loaded into the Vitron Tissue Slicer ${ }^{\mathrm{TM}}$ from Vitron Inc. (Tucson, AZ), and $250 \mu \mathrm{m}$ thick slices were prepared [15]. Slices were cut using a $45-\mathrm{mm}$ rotary blade, floated into ice cold oxygenated V-7 preservation buffer, and pre-incubated in the presence of serum free Williams Medium (WE) (Sigma Chemical Co., St. Louis, MO) containing D-glucose and gentamicin with $95 \%$ oxygen $/ 5 \% \mathrm{CO}_{2}$ (carbogen) at $37{ }^{\circ} \mathrm{C}$ for $30 \mathrm{~min}$. For some studies, slices were taken at this time point and were designated as Time $0\left(t_{0}\right)$ slices. The rest of the slices were loaded onto titanium-screen rollers from Vitron, Inc. (Tucson, AZ) and inserted into sterile $20 \mathrm{ml}$ glass vials containing $1.7 \mathrm{ml}$ of WE media. The vials were capped with lids containing a $1 \mathrm{~mm}$ hole for the infusion of oxygen. This assembly was placed horizontally into the Dynamic Organ Culture incubator from Vitron Inc. (Tucson, AZ) and incubated at $37{ }^{\circ} \mathrm{C}$ in the presence of carbogen using a flow rate of $1.5 \mathrm{lpm}$.

\subsection{Incubation of slices with ethanol}

Following pre-incubation with WE, slices were incubated with media only (control), media + $25 \mathrm{mM}$ ethanol (ethanol), media + $25 \mathrm{mM}$ ethanol + $0.50 \mathrm{mM}$ 4-methylpyrazole (ethanol + 4$\mathrm{MP}$ ), or media + $0.50 \mathrm{mM}$ 4-methylpyrazole (control + 4-MP). The addition of 4-MP was used in these studies as it is a general inhibitor of ethanol metabolism. These slices were placed in the Dynamic Organ Culture incubator and cultured at $37{ }^{\circ} \mathrm{C}$ for up to $96 \mathrm{~h}$, and every $24 \mathrm{~h}$ the appropriate media was replenished. In order to determine the concentration of ethanol and acetaldehyde in the media, the supernatant was analyzed using headspace gas chromatography [16].

\subsection{Viability assays}

Slice viability was determined by measuring adenosine triphosphate (ATP) and lactate dehydrogenase (LDH) levels. For the ATP assay, slices were harvested at the appropriate times, placed into $70 \%$ ethanol/2 mM EDTA, flash frozen, and stored at $-70{ }^{\circ} \mathrm{C}$ until assayed. Samples were thawed on ice, sonicated, and diluted in $0.1 \mathrm{M}$ Tris- $\mathrm{HCl} / 2 \mathrm{mM}$ ETDA prior to use in the ATP Bioluminescence Assay Kit CLSII (Roche Applied Science, Penzberg, Germany). ATP levels were detected using a Modulus Microplate Luminometer from Turner Biosystems (Sunnyvale, CA).

For LDH determination, supernatant was collected and frozen at $-70{ }^{\circ} \mathrm{C}$. The slice was solubilized in WE containing $2 \%$ Triton X-100 and LDH determined using a Cytotoxicity Detection Kit (LDH) (Roche Applied Science, Penzberg, Germany). The absorbance of the samples was measured at $490 \mathrm{~nm}$ using a MRX II plate reader with Revelation Software ${ }^{\mathrm{TM}}$ 
(Dynex Technologies, Chantilly, VA). All protein concentrations from the slices were determined using a BCA Protein Assay kit from Pierce (Rockford, IL). To calculate the \% Cytotoxicity at subsequent $24 \mathrm{~h}$ time points, the LDH in the media was divided by the total LDH in the PCLS and multiplied by 100 .

\subsection{ADH/ALDH activity}

Slices were harvested at the time points indicated, washed in PBS ( $\mathrm{pH} 7.4$ ), lysed in $1 \%$ Triton X-100, and sonicated. For the $\mathrm{ADH}$ assay, protein concentrations were adjusted to 50-100 $\mu \mathrm{g}$ and incubated at $37{ }^{\circ} \mathrm{C}$ in the presence of $10 \mathrm{mM}$ ethanol, $3 \mathrm{mM}$ $\mathrm{NAD}^{+}$, and $0.5 \mathrm{M}$ Tris- $\mathrm{HCl}\left(\mathrm{pH}\right.$ 7.4). Conversion of $\mathrm{NAD}^{+}$to NADH was measured by the change in optical density at $340 \mathrm{~nm}$ using a Cary 50 spectrophotometer (Varian Inc., Palo Alto, CA) [17]. ALDH activity was determined by placing the slice into $1 \mathrm{ml}$ of buffer containing $100 \mathrm{mM} \mathrm{NaPO}_{4}(\mathrm{pH} 7.4$ ), $3 \mathrm{mM} \mathrm{NAD}^{+}$, and $10 \mathrm{mM}$ pyrazole. The reaction was initiated by adding propionaldehyde to a final concentration of $25 \mu \mathrm{M}$ (low $K_{\mathrm{m}}$ enzyme) or $1 \mathrm{mM}$ (total enzyme activity). Conversion of $\mathrm{NAD}^{+}$to $\mathrm{NADH}$ was determined by the change in optical density at $340 \mathrm{~nm}$ using a Cary 50 spectrophotometer [6].

\subsection{Cytochrome P450 2E1 (CYP2E1) assay}

Microsomes were prepared from slices using a modified protocol from Omura and Kamth et al. $[18,19]$. Briefly, slices were added to a $1.15 \% \mathrm{KCl}$ solution, sonicated, subjected to differential centrifuged to obtain the microsomal fraction, and protein concentration determined by the method of Lowry et al. [20]. CYP2E1 activity was determined using the $p$ nitrophenol (PNP) (Sigma Chemical Co., St. Louis, MO) oxidation assay described by $\mathrm{Wu}$ and Cederbaum [21]. Microsomal protein was added to $0.2 \mathrm{mM}$ PNP, $1 \mathrm{mM}$ NADPH (Sigma Chemical Co., St. Louis, MO), and incubated at $37^{\circ} \mathrm{C}$ for $1 \mathrm{~h}$. The reaction was stopped using $30 \%$ trichloroacetic acid, centrifuged, and $10 \mathrm{~N} \mathrm{NaOH}$ was added to the remaining supernatant. Activity was obtained by measuring the absorbance at $546 \mathrm{~nm}$ using a Beckman DU-70 spectrophotometer.

Immunoblotting techniques were used to determine microsomal CYP2E1 expression [9]. Microsomal protein $(5 \mu \mathrm{g})$ was loaded onto a 10\% SDS polyacrylamide gel, transferred onto PVDF membrane, and blocked in Blotto. The primary antibody, rabbit anti-CYP2E1 (Chemicon, Temecula, CA) was incubated overnight at $4{ }^{\circ} \mathrm{C}$ followed by $1 \mathrm{~h}$ incubation with an IR-labeled secondary anti-rabbit IgG antibody. Blots were washed, dried and scanned using an Odyssey IR Scanner (Li-Cor, Lincoln, NE). Densitometric analysis was performed using Odyssey imaging software (LiCor, Lincoln, NE) and the data are expressed in arbitrary densitometric units/ $\mu \mathrm{g}$ of protein.

\subsection{Cellular redox state and albumin secretion}

Supernatant from liver slices incubated up to $96 \mathrm{~h}$ under various conditions was assayed for the presence of lactate or pyruvate using assay kits from Biovision (Mountain View, CA) to assess the cellular redox state. Briefly, $50 \mu \mathrm{l} /$ well of each sample was incubated with $50 \mu \mathrm{l} /$ well of assay kit reagent in conjunction with the lactate or pyruvate enzyme. The reaction was allowed to take place for $30 \mathrm{~min}$ and the levels of lactate or pyruvate were determined by absorbance at $570 \mathrm{~nm}$. Plates were analyzed using a MRX II plate reader with Revelation Software (Dynex Technologies, Chantilly, VA).

Supernatant was used to analyze PCLS for albumin secretion using a Rat Albumin Quantitative ELISA Kit from Bethyl Laboratories, Inc. (Montgomery, TX). This assay was performed by coating a 96 well plate with a capture antibody (sheep anti-Rat Albumin). Plates were blocked with BSA, and the albumin standard or sample were added. A secondary antibody was added (HRP conjugated Sheep anti-Rat Albumin) and the plate was developed using TMB peroxidase substrate (Pharmingen, San Diego, CA). Absorbance was detected at $450 \mathrm{~nm}$ using a MRX II plate reader with Revelation Software (Dynex Technologies, Chantilly, VA).

\subsection{Triglyceride analysis}

At indicated time points, supernatant was removed and slices were washed in PBS ( $\mathrm{pH}$ 7.4). Slices were placed in PBS containing $0.5 \%$ Triton-X100, sonicated, and the equivalent of $300 \mu \mathrm{g}$ of protein was assayed for triglycerides using the serum triglyceride kit from Sigma Chemical Co. (St. Louis, MO). Triglycerides in each sample were hydrolyzed by lipase and the resulting free glycerol was calculated against a glycerol standard at $540 \mathrm{~nm}$ using the Cary 50 spectrophotometer.

\subsection{Oil Red O staining}

For Oil Red O staining, slices were flash frozen in OCT (Sigma Chemical Co., St. Louis, MO), sectioned and gently placed onto slides. Oil Red O was incubated with the sections, washed, and the presence or absence of fat content analyzed by light microscopy on a Nikon Microphot-FXA microscope by a pathologist. Photographs were taken using a Colorview II Olympus Camera with Analysis Software, at a final magnification of $325 \times$.

\subsection{Statistical analysis}

The results are expressed as means \pm S.E.M. Statistical significance was achieved if $P$-values were less than 0.05 . All statistical analysis was performed using the SigmaStat (Jandel Scientific, 2002) program and one-way or multiple ANOVA where appropriate.

\section{Results}

The first step in assessing the utility of precision-cut liver slices as a model of alcoholic liver disease (ALD) was to determine their viability under different conditions and for various lengths of time. Therefore, PCLS were prepared and their viability over a 96 -h period assessed using adenosine triphosphate levels and lactate dehydrogenase release. ATP was chosen as it represents the ability of the slices to maintain an energy source and as such is a measure of live cells. In contrast, cell death was quantified by measuring the amount of LDH released into the medium. These assays represent two 


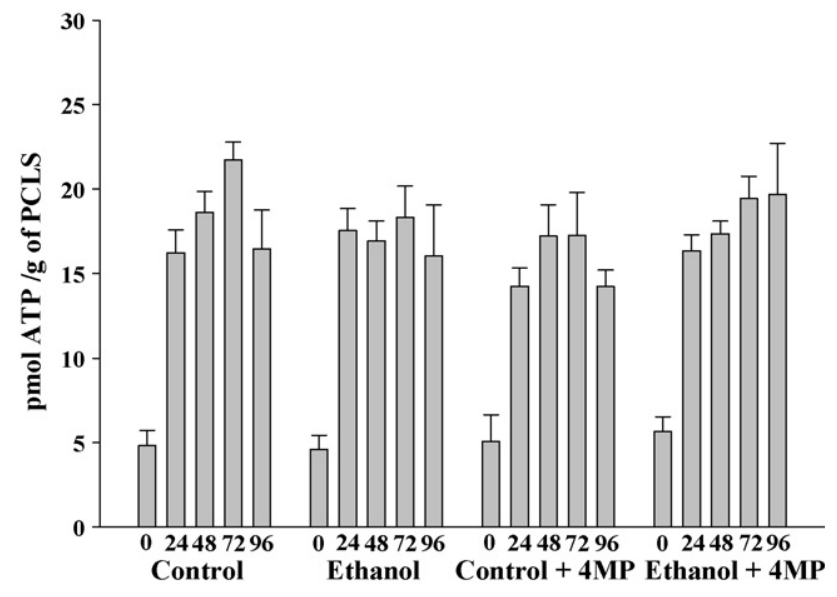

Fig. 1 - ATP production from rat precision-cut liver slices (PCLS). PCLS were cultured at $t_{0}, 24,48,72$ and $96 \mathrm{~h}$ in the absence of ethanol (control), presence of $25 \mathrm{mM}$ ethanol (ethanol), absence of $25 \mathrm{mM}$ ethanol but in the presence of $0.50 \mathrm{mM}$ 4-MP (control + 4-MP), and in the presence of both $25 \mathrm{mM}$ ethanol and $0.50 \mathrm{mM}$ 4-MP (ethanol + 4-MP). ATP activity was determined as described in Section 2. Data are expressed as the mean ( $\rho \mathrm{mol}$ ATP/ $\mu \mathrm{g}$ of PCLS protein) \pm S.E.M. of five separate experiments. There were no significant differences observed at the various time points among the four groups.

different ways of measuring viability. At time $0\left(t_{0}\right)$ all slices showed a decreased level of ATP (approximately 4.5-5.6 pmol ATP/ $\mu$ g of protein). PCLS at this time (30 min of pre-incubation) most likely reflects acute changes related to the process of the preparing the liver, physical trauma during the slicing, and a "washout" period during which the PCLS are equilibrating. However, as shown in Fig. 1, all liver slices produced ATP and maintained these levels over the 96 - $h$ period.

Measurement of LDH activity (Fig. 2) showed that cell death (\% Cytotoxicity) in control PCLS was maintained between 0 and $7.8 \%$ for up to $96 \mathrm{~h}$. Incubation with $25 \mathrm{mM}$ ethanol increased the levels of cytotoxicity reaching a maximum of $11.9 \%$ at 72 and $96 \mathrm{~h}$. These levels were significantly different from control levels at all time points assayed. The addition of 4-methyl-pyrazole (4-MP) to the control and ethanol treated samples resulted in a decrease in the \% Cytotoxicity in both control and ethanol-treated samples.

Ethanol metabolism and ADH activity were next examined at the different time points (Fig. 3). At time zero, media containing $25 \mathrm{mM}$ ethanol was added. Every $24 \mathrm{~h}$ thereafter, the media was totally removed and replaced with fresh media containing $25 \mathrm{mM}$ ethanol. In this way, it was possible to assess how much ethanol was metabolized over a 24 -h period. During the first $24 \mathrm{~h}$, the PCLS metabolized (as determined by gas chromatography) $15.18 \mu \mathrm{mol} /(24 \mathrm{~h} \mathrm{mg})$ of PCLS protein and this level was maintained for the next $48 \mathrm{~h}$ (48 and $72 \mathrm{~h}$ time points). At $96 \mathrm{~h}$ the PCLS appear to have a decrease in their ability to metabolize ethanol to $9.43 \mu \mathrm{mol} /(24 \mathrm{~h} \mathrm{mg})$ of PCLS protein which may be related to the decrease in viability. The addition of 4-MP to PCLS treated with ethanol at the onset of the experiment to determine whether the clearance of

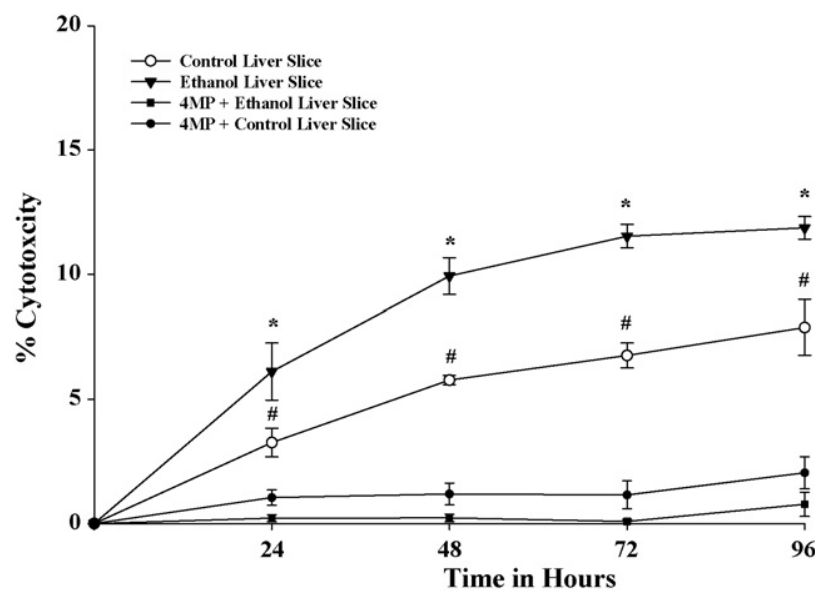

Fig. 2 - LDH activity in rat pecision-cut liver slices. PCLS were cultured at $t_{0}, 24,48,72$ and $96 \mathrm{~h}$ in the absence of ethanol (control, open circles), presence of $25 \mathrm{mM}$ ethanol (ethanol, closed triangles), absence of $25 \mathrm{mM}$ ethanol but in the presence of $0.50 \mathrm{mM}$ 4-MP (control + 4-MP-closed circles), and in the presence of both $25 \mathrm{mM}$ ethanol and $0.50 \mathrm{mM}$ 4-MP (ethanol + 4-MP-closed squares). LDH activity (\% Cytotoxicity) was determined as described in Section 2. Data are expressed as the mean \% Cytotoxicity \pm S.E.M. of five separate experiments. Ethanol significantly increased the \% Cytotoxicity when compared to other three groups, ${ }^{*} \mathrm{P}<0.05$. Ethanol and control PCLS groups compared to ethanol + 4-MP or control + 4-MP PCLS. Additionally, the control PCLS showed significantly higher \% Cytotoxicity compared to the ethanol + 4-MP or control + 4-MP PCLS, " $P<0.05$.

ethanol was due to metabolism showed that the metabolic rate of ethanol was significantly decreased at all times examined.

The metabolism of ethanol in the liver is primarily dependent upon ADH activity. At 48, 72 and $96 \mathrm{~h}$ the $\mathrm{ADH}$ activity of PCLS exposed to ethanol was decreased when compared to control and ethanol + 4-MP treated slices, but were only significantly lower at 72 and $96 \mathrm{~h}$ (Table 1). All ADH activities were lower than at time 0 , but were only significantly lower for all slices at 72 and $96 \mathrm{~h}$.

Ethanol metabolism by the liver produces acetaldehyde, an extremely reactive compound implicated in ethanol-induced liver injury [9,22-24]. Based on the results above, the production of acetaldehyde was investigated. As shown in Fig. 4, acetaldehyde levels were detectable within $24 \mathrm{~h}$ reaching about $4.2 \mu \mathrm{M}$ concentrations and continued to increase at $48(22.9 \mu \mathrm{M}), 72(47.1 \mu \mathrm{M})$ and $96(64.3 \mu \mathrm{M}) \mathrm{h}$. The production of acetaldehyde was completely inhibited by the addition of $0.50 \mathrm{mM}$ 4-MP, indicating the acetaldehyde produced was from ethanol metabolism.

Because the levels of acetaldehyde are partially dependent upon their metabolism by cellular ALDH enzymes, the total and low $K_{\mathrm{m}}$ ALDH activities were investigated (Table 1). The total ALDH enzyme activities of PCLS treated under all conditions showed significantly lower activities when compared to $t_{0}$. Additionally, total ALDH activity was further 


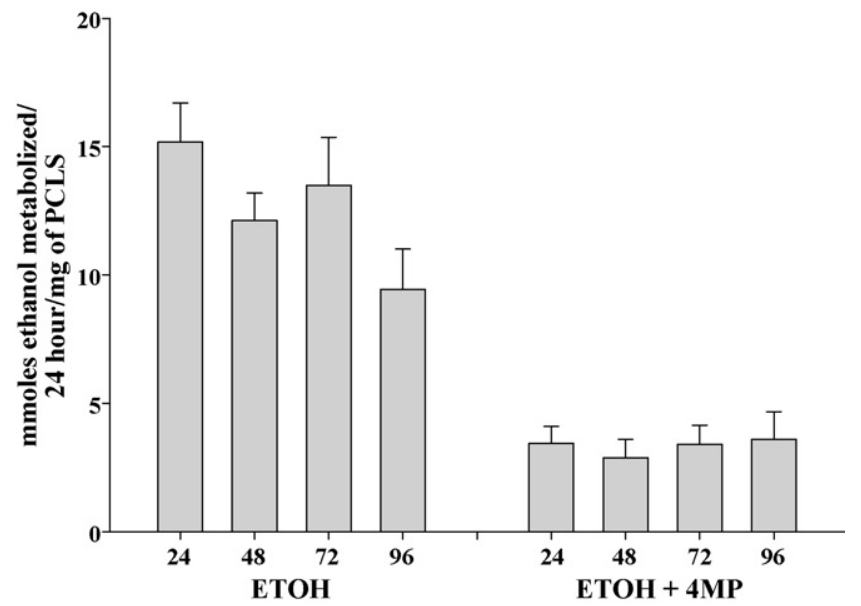

Fig. 3 - Ethanol metabolism by rat precision-cut liver slices. PCLS were cultured at 24, 48, 72 and $96 \mathrm{~h}$ in the presence of $25 \mathrm{mM}$ ethanol (ethanol), and in the presence of both $25 \mathrm{mM}$ ethanol and $0.50 \mathrm{mM}$ 4-MP (ethanol + 4-MP). Since control PCLS do not metabolize ethanol, the data for control and control + 4-MP are not shown. Media were changed every $24 \mathrm{~h}$ and assessed for ethanol concentrations $(\mu \mathrm{mol} / \mathrm{mg})$ by headspace gas chromatography. Data are expressed as the mean \pm S.E.M. Micromoles of ethanol metabolized/(24 h mg) of PCLS protein of five separate experiments. The addition of 4-MP significantly inhibited ethanol metabolism at all times, ${ }^{*} \mathrm{P}<0.01$. significantly decreased in PCLS treated with ethanol at 48 and $72 \mathrm{~h}$. The addition of 4-MP maintained total ALDH equivalent to the levels for 24 to $48 \mathrm{~h}$. Similar results were found for the low $K_{m}$ ALDH activities showing a decrease by half after $24 \mathrm{~h}$, and remained consistent for up to $96 \mathrm{~h}$.

CYP2E1, a cytochrome P450 enzyme implicated in ethanolinduced liver injury was examined for protein expression (Fig. 5A) by immunoblot analysis [9]. At $24 \mathrm{~h}$, the control PCLS contained about $1 / 3$ the CYP2E1 expression (0.335 relative counts/ $\mu \mathrm{g}$ of $t_{0}$ PCLS) that was observed in the $t_{0}$ sample. This expression decreased slightly at $48 \mathrm{~h}$ and then decreased by approximately $25 \%$ every $24 \mathrm{~h}$ thereafter. In contrast, the PCLS exposed to ethanol retained more CYP2E1 expression $(0.4835$ relative counts/ $\mu \mathrm{g}$ of $\mathrm{t}_{0}$ PCLS) at $24 \mathrm{~h}$, with this level decreasing to those observed for control PCLS slices at 48, 72 and $96 \mathrm{~h}$. Interestingly, the addition of 4-MP to PCLS in the presence or absence of ethanol appeared to maintain the CYP2E1 expression levels near to those observed for ethanol PCLS at $24 \mathrm{~h}$.

Protein expression of an enzyme does not necessarily reflect whether the CYP2E1 was active. Therefore, activity (Fig. 5B) was assessed using the $p$-nitrophenol (PNP) oxidation assay [21]. In general, the profile observed with protein expression (Fig. 5A) showed a concomitant decrease in activity (Fig. 5B) in both the control and ethanol PCLS. The addition of 4-MP to control and ethanol PCLS maintained the CYP2E1 activities at levels observed for ethanol PCLS at $24 \mathrm{~h}$ for the first 24 to $48 \mathrm{~h}$. This again reflected the protein expression at these time points (Fig. 5A). In contrast, the activities began to decrease at $72 \mathrm{~h}$ until they attained control and ethanol PCLS activity levels by $96 \mathrm{~h}$.

The metabolism of ethanol by $\mathrm{ADH}$ and acetaldehyde by ALDH generates NADH which can result in a reduced redox

Table 1 - Comparison of ADH and ALDH activities in rat precision-cut liver slices lysates from PCLS at $t_{0}, 24,48,72$ and $96 \mathrm{~h}$ were prepared and the activities of ADH and ALDH were compared

\begin{tabular}{|c|c|c|c|}
\hline Sample (h) & ADH activity & Total ALDH activity & Low $K_{\mathrm{m}}$ ALDH activity \\
\hline Time 0 & $15.39 \pm 1.16$ & $7.59 \pm 0.33$ & $1.66 \pm 0.09$ \\
\hline Control 24 & $10.69 \pm 0.71^{*}$ & $4.16 \pm 0.16^{*}$ & $0.81 \pm 0.06^{*}$ \\
\hline Ethanol 24 & $11.40 \pm 0.58^{*}$ & $4.12 \pm 0.18^{*}$ & $0.75 \pm 0.06^{*}$ \\
\hline Control + 4-MP 24 & $12.24 \pm 2.35$ & $4.65 \pm 0.36^{*}$ & $0.98 \pm 0.15^{*}$ \\
\hline Ethanol + 4-MP 24 & $12.23 \pm 2.54$ & $4.88 \pm 0.27^{*}$ & $0.96 \pm 0.20^{*}$ \\
\hline Control 48 & $11.54 \pm 1.91$ & $3.82 \pm 0.41^{*, \$}$ & $0.79 \pm 0.09^{*}$ \\
\hline Ethanol 48 & $9.13 \pm 2.04$ & $2.70 \pm 0.41^{*, \#, \$}$ & $1.01 \pm 0.13^{*}$ \\
\hline Control + 4-MP 48 & $12.89 \pm 3.63$ & $4.44 \pm 0.44^{*}$ & $1.01 \pm 0.24^{*}$ \\
\hline Ethanol + 4-MP 48 & $12.04 \pm 2.84$ & $4.49 \pm 0.35^{*}$ & $1.11 \pm 0.21^{*}$ \\
\hline Control 72 & $11.43 \pm 0.57^{*, \$}$ & $2.89 \pm 0.16^{*}$ & $0.75 \pm 0.04^{*}$ \\
\hline Ethanol 72 & $8.01 \pm 0.90^{*, \#, \$}$ & $2.04 \pm 0.21^{*, \#, \$}$ & $0.79 \pm 0.17^{*, \$}$ \\
\hline Control + 4-MP 72 & $12.71 \pm 1.38^{*}$ & $3.47 \pm 0.36^{*}$ & $1.11 \pm 0.27^{*}$ \\
\hline Ethanol + 4-MP 72 & $12.45 \pm 1.35^{*}$ & $4.11 \pm 0.44^{*}$ & $1.14 \pm 0.33^{*}$ \\
\hline Control 96 & $11.01 \pm 0.87^{*, \$}$ & $2.73 \pm 0.14^{*}$ & $0.84 \pm 0.18^{*}$ \\
\hline Ethanol 96 & $7.97 \pm 1.59^{*, \#, \$}$ & $2.51 \pm 0.14^{*}$ & $1.04 \pm 0.18^{*}$ \\
\hline Control + 4-MP 96 & $16.09 \pm 3.29$ & $3.39 \pm 0.44^{*}$ & $1.07 \pm 0.35^{*}$ \\
\hline Ethanol + 4-MP 96 & $10.06 \pm 1.43^{*}$ & $3.05 \pm 0.27^{*}$ & $1.02 \pm 0.12^{*}$ \\
\hline
\end{tabular}

${ }^{*} \mathrm{P}>0.05$ Significant compared to $\mathrm{T}=0 .{ }^{*} \mathrm{P}>0.05$ Significant compared to control slice. ${ }^{\$} \mathrm{P}>0.05$ Significant compared to control or ethanol 4MP. To determine if ethanol treatment affected these activities, PCLS were incubated in the absence of ethanol (control), presence of $25 \mathrm{mM}$ ethanol (ethanol), and in the presence of both $25 \mathrm{mM}$ ethanol and $0.50 \mathrm{mM} \mathrm{4-MP} \mathrm{(ethanol} \mathrm{+} \mathrm{4-MP).} \mathrm{All} \mathrm{activities} \mathrm{are} \mathrm{expressed} \mathrm{in} \mathrm{nmol} \mathrm{of}$ $\mathrm{NAD}+$ oxidized/(min mg protein) and are shown as the mean \pm S.E.M. All determinations were performed in duplicate for each of the five samples. Significantly decreased compared to the $t_{0}$ time point, ${ }^{*} P<0.05$. Significantly decreased compared to the corresponding control PCLS, ${ }^{\#} \mathrm{P}<0.05$. Significantly decreased when compared to the PCLS slices incubated with 4-MP alone (control + 4-MP) or ethanol + 4-MP, ${ }^{\$} \mathrm{P}<0.05$. 


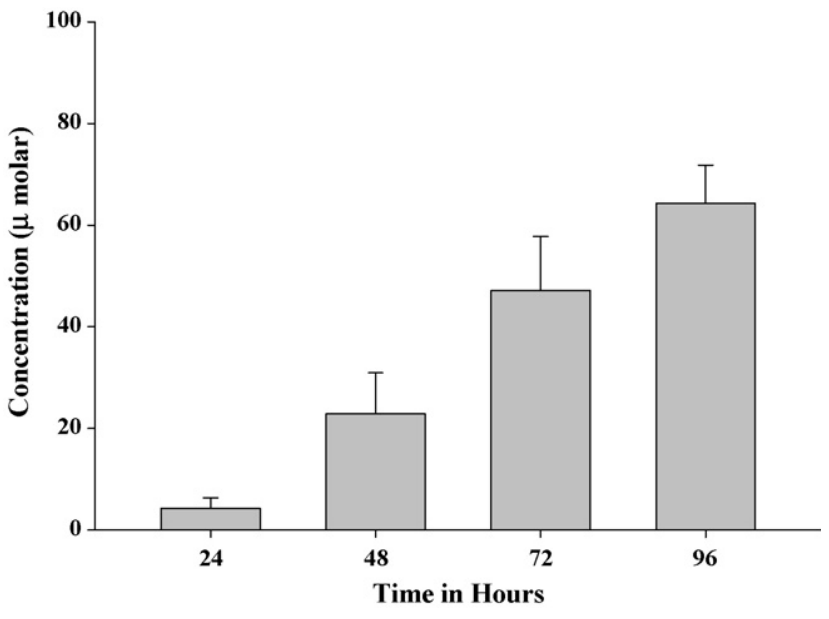

Fig. 4 - Acetaldehyde levels following incubation of rat precision-cut liver slices with ethanol. PCLS were cultured $24,48,72$ and $96 \mathrm{~h}$ in the presence of $25 \mathrm{mM}$ ethanol (ethanol). The control and control + 4-MP groups do not metabolize ethanol to produce acetaldehyde. Additionally, the addition of both $25 \mathrm{mM}$ ethanol and $0.50 \mathrm{mM} 4-\mathrm{MP}$ (ethanol + 4-MP) resulted in the total inhibition of the production of acetaldehyde from ethanol. So, the data from these three groups are not shown. Media was changed every $24 \mathrm{~h}$ and assessed for acetaldehyde concentrations ( $\mu \mathrm{mol}$ ) by headspace gas chromatography. Data are expressed as the mean \pm S.E.M. of five separate experiments.

state [25]. To determine the effects of ethanol metabolism on the PCLS redox state, the lactate/pyruvate $\left(\mathrm{NADH} / \mathrm{NAD}^{+}\right)$ratio in PCLS was determined and found to be significantly increased after ethanol exposure at all times examined (Fig. 6) when compared to control PCLS. Incubation of the PCLS in the presence of ethanol and 4-MP completely reversed the ethanol-induced change in redox state. These results are similar to those reported with cell lines transfected with $\mathrm{ADH}$ $[26,27]$, from isolated hepatocytes [17], and from the WIF-B cell line [9].

PCLS were incubated in the presence and absence of both ethanol and 4-MP for 24, 48, 72 and $96 \mathrm{~h}$, and examined for cellular triglyceride levels. By $24 \mathrm{~h}$, the levels of triglycerides in ethanol-treated PCLS were significantly elevated approximately twofold over the control level (Fig. 7). These levels continued to increase over the $96 \mathrm{~h}$ incubation period, reaching a maximum of a $300 \%$ increase. The addition of $4-\mathrm{MP}$ in the presence of ethanol reversed the ethanol-induced increase in triglyceride content, indicating that the accumulation of triglycerides was a result of ethanol metabolism.

Oil Red O staining of PCLS treated with ethanol confirms the biochemical findings discussed above. Fig. 8B shows the control PCLS after $48 \mathrm{~h}$ of culture and there is a small amount of fatty infiltration as compared to the $t_{0}$ slice (Fig. 8A). In contrast, PCLS exposed to ethanol for $48 \mathrm{~h}$ showed a substantial increase in the staining by Oil Red O (Fig. 8C) similar to that observed in the triglyceride data, that was abrogated when 4-MP was added to the incubation media containing ethanol (Fig. 8D).
It was important to determine if the PCLS were able to maintain cellular function and whether ethanol has significant effects on this function. One of the functions that are commonly measured is the secretion of albumin. As shown in Fig. 9, albumin is secreted by all PCLS regardless of their treatment. However, ethanol treatment of PCLS significantly decreased the secretion by about $50 \%$ when compared to controls. Finally, the addition of 4-MP to the media reversed the effects of ethanol treatment indicating that the metabolism of ethanol was involved in the decrease in albumin secretion.

\section{Discussion}

Alcohol abuse results in various forms of liver injury, but research on the mechanisms of alcoholic liver disease (ALD) have been hampered by the lack of an appropriate in vitro culture model in which to conduct in depth and specific mechanistic studies. Although primary hepatocytes in culture, hepatoma cell lines and WIF-B cells have provided valuable information, they do not always provide the ability to study intracellular interactions and the regulatory factors associated with naturally occurring extracellular matrices, and in some instances they rapidly lose specific liver gene expression [3-9]. Others have used liver slices in the past to attempt to investigate the effects of ethanol on the liver; however, as with isolated cells and cell lines, these slices rapidly lost all normal liver function [16,28-31]. Recently, investigators have developed precision-cut liver slices (PCLS), incubated under high oxygen content, for investigating the effects of various toxins on the liver $[10,14,32,33]$. As described in this manuscript, we have tested the applicability of using PCLS as a model for studying the mechanism(s) of alcoholinduced liver injury.

Under the experimental conditions of this study, PCLS remained functional and viable over a $96-\mathrm{h}$ time period. ATP was produced and levels of ATP were maintained at high levels throughout the entire $96 \mathrm{~h}$ of incubation. Leakage of LDH was minimal; however, slight increases were observed at the later time points. Importantly, albumin was produced and secreted over the entire time-course, indicating that the PCLS were functional. Addition of $25 \mathrm{mM}$ ethanol to the PCLS did not appear to affect their ability to maintain ATP levels, and leakage of LDH was only slightly increased by ethanol, indicating that ethanol had only minimal effects on cell viability. It should be noted, that it was necessary to use the incubator and roller inserts as described by [34] in order to maintain PCLS function for longer than $24 \mathrm{~h}$. Additionally, the V7 medium used for cutting these slices and the addition of new media daily was imperative in maintaining the viability of the PCLS. Importantly, in our hands the use of alternative technological approaches; submerged slices in six-well plates on a rocker platform [35], Transwell Permeable Supports (Corning Inc. Acton, MA) on a rocker platform [14], Transwell plates with nitrocellulose [36], or home-made incubators to increase oxygen content [32] could only be used for short term cultures.

A critical aspect of any model designed to study alcoholic hepatotoxicity is the evaluation of ethanol metabolism. The 

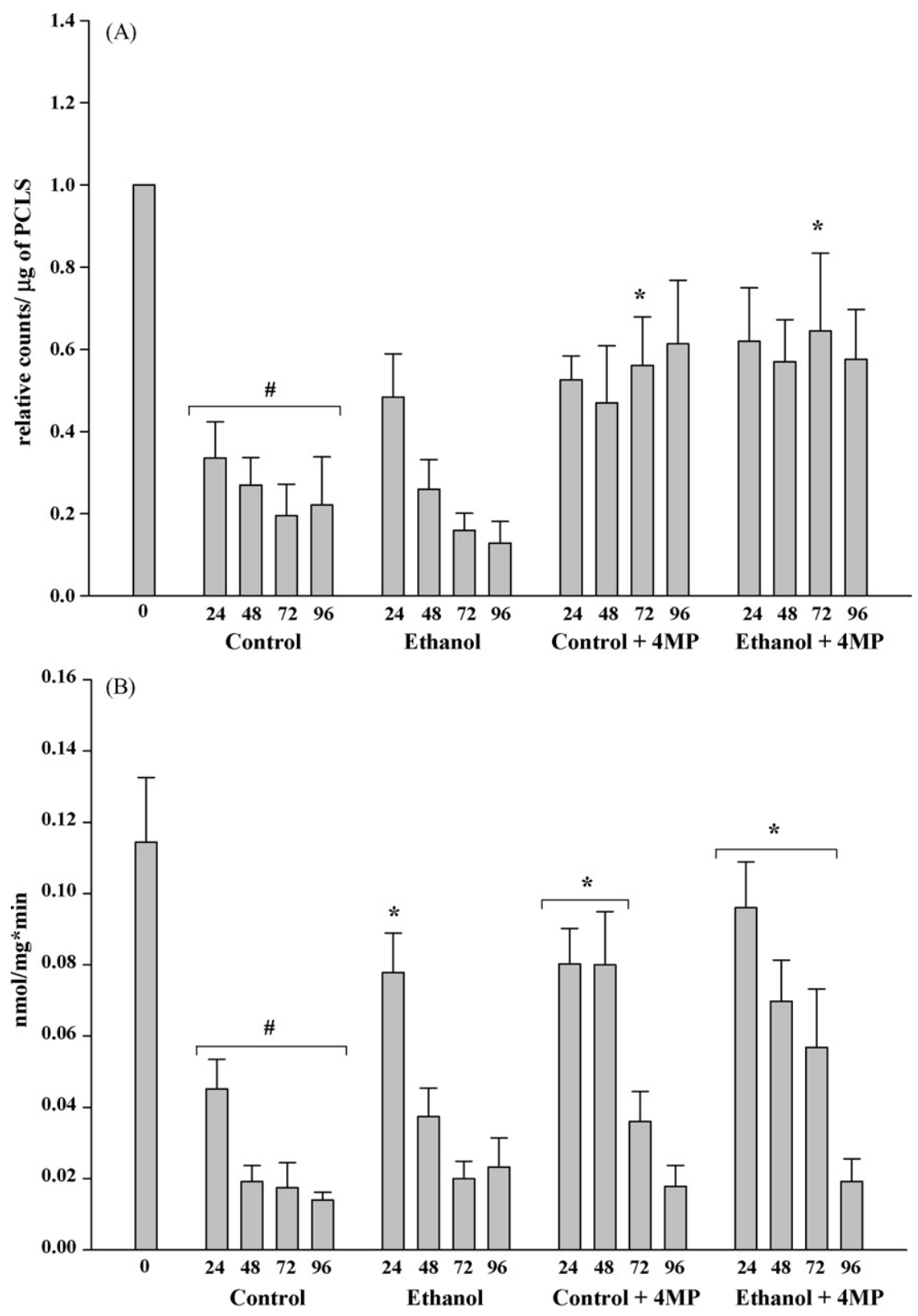

Fig. 5 - (A) CYP2E1 expression in microsomes from rat precision-cut liver slices. PCLS were cultured at $t_{0}, 24,48,72$ and $96 \mathrm{~h}$ in the absence of ethanol (control), absence of ethanol but the addition of $0.50 \mathrm{mM} 4-\mathrm{MP}$ (control + 4-MP), presence of $25 \mathrm{mM}$ ethanol (ethanol), and in the presence of both $25 \mathrm{mM}$ ethanol and $0.50 \mathrm{mM}$ 4-MP (ethanol + 4-MP). Microsomes were prepared as outlined in Section 2, loaded on SDS-PAGE gels ( $5 \mu$ grotein per lane), and analyzed by immunoblotting and densitometry as described in Section 2. The data are expressed as the mean \pm S.E.M. of five separate experiments. Significantly decreased as compared to $t_{0},{ }^{\#} P<0.001$. Significantly increased as compared to the corresponding control PCLS, ${ }^{*} P<0.05$. (B) CYP2E1 activity in microsomes from rat precision-cut liver slices. PCLS were cultured at $t_{0}, 24,48,72$ and $96 \mathrm{~h}$ in the absence of ethanol (control), absence of ethanol but the addition of $0.50 \mathrm{mM}$ 4-MP (control + 4-MP), presence of $25 \mathrm{mM}$ ethanol (ethanol), and in the presence of both $25 \mathrm{mM}$ ethanol and 0.50 mM 4-MP (ethanol + 4-MP). Microsomes were assayed for the presence of CYP2E1 using $p$-nitrophenol oxidation as described in Section 2. The data are expressed as the mean \pm S.E.M. of five separate experiments. Significantly decreased as compared to $t_{0},{ }^{\#} P<0.001$. Significantly increased as compared to the corresponding control PCLS, ${ }^{*} \mathrm{P}<0.05$.

results for these studies demonstrated that PCLS metabolized ethanol at virtually the same rate for up to $72 \mathrm{~h}$ after which it decreased slightly for the final $24 \mathrm{~h}$ of incubation. Importantly, the presence of the known inhibitor of ethanol metabolism, 4MP, dramatically reduced the metabolism of ethanol by PCLS.
The rate of ethanol metabolism in PCLS was comparable with those seen in freshly isolated hepatocytes [17]. Examination of acetaldehyde (a metabolite of ethanol and a possible mediator of liver injury) concentrations showed that ethanol metabolism resulted in levels of acetaldehyde ranging from $20 \mu \mathrm{M}$ at 


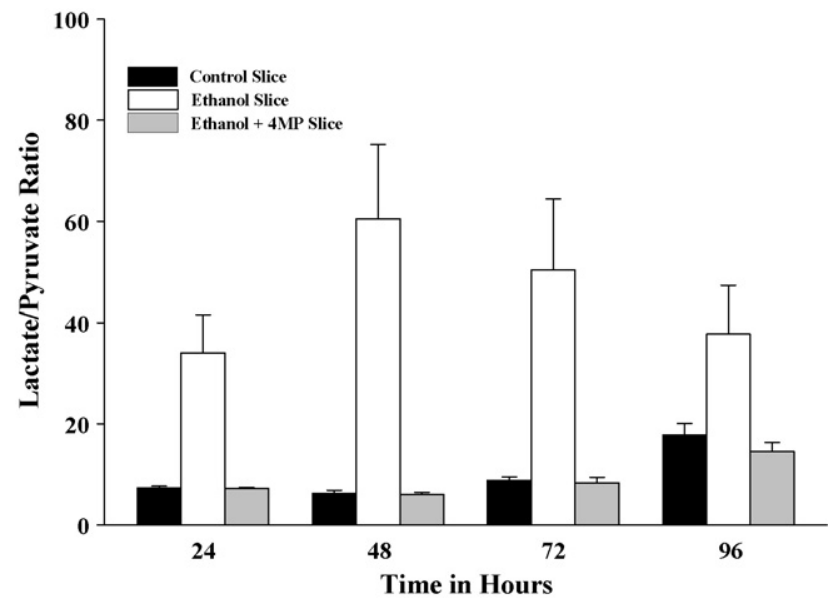

Fig. 6 - Redox ratio (lactate/pyruvate) in rat precision-cut liver slices. PCLS were cultured at 24, 48, 72 and $96 \mathrm{~h}$ in the absence of ethanol (control, solid bars), presence of $25 \mathrm{mM}$ ethanol (ethanol, open bars), and in the presence of both $25 \mathrm{mM}$ ethanol and $0.50 \mathrm{mM}$ 4-MP (ethanol + 4-MP-shaded bar). At the various time points the lactate and pyruvate concentrations were determined and the redox ratio calculated. The control + 4-MP group were not different from the control PCLS (data not shown). The cellular redox state was determined as described in Section 2. Data are expressed as the mean lactate/pyruvate (NADH/NAD+) ratio \pm S.E.M. of five separate experiments. Significantly increased for ethanol treated PCLS compared to all other groups, ${ }^{*} \mathrm{P}<0.01$.
$48 \mathrm{~h}$ to $60 \mu \mathrm{M}$ at $96 \mathrm{~h}$ of incubation. These concentrations are within the range of values reported for acetaldehyde levels observed during ethanol metabolism in vivo [37,38]. These results demonstrated that ethanol metabolism by PCLS are consistent with the data showing that PCLS were able to maintain both $\mathrm{ADH}$ and ALDH activities during incubation. $\mathrm{ADH}$ activities appeared to remain relatively consistent over the time-course of incubation; however, ALDH activities did decrease over the course of these time points, and most likely explains the increase of acetaldehyde in the media over time.

Another enzyme capable of metabolizing ethanol is CYP2E1, and this enzyme has been proposed to play a role in ethanol-induced liver injury [39]. PCLS did express CYP2E1 during incubation; however, the levels and activities of CYP2E1 were reduced to about $20-40 \%$ of the level of a freshly prepared liver samples. Despite this rather large decrease in CYP2E1 activity, ethanol metabolism was maintained at a relatively constant rate, indicating that ethanol metabolism occurred primarily via the $\mathrm{ADH}$ pathway. In addition, the known in vivo inducing effects of agents, such as ethanol and 4-MP, on CYP2E1 were also observed when PCLS were treated with these agents.

In order to further evaluate the applicability of PCLS as a model for ethanol-induced hepatotoxicity, known detrimental effects of ethanol on hepatic function $[1,2,40,41]$ were tested. Incubation of PCLS with ethanol resulted in a more reduced metabolic state, i.e. increased NADH/NAD + ratio (lactate/ pyruvate). Secondly, ethanol treatment impaired the secretion of albumin by PCLS. Finally, ethanol treatment of PCLS resulted in a fatty liver. This finding was ascertained by both morphological and biochemical analysis of triglycerides. In this regard, triglyceride levels progressively increased during incubation in the presence of ethanol, reaching an almost

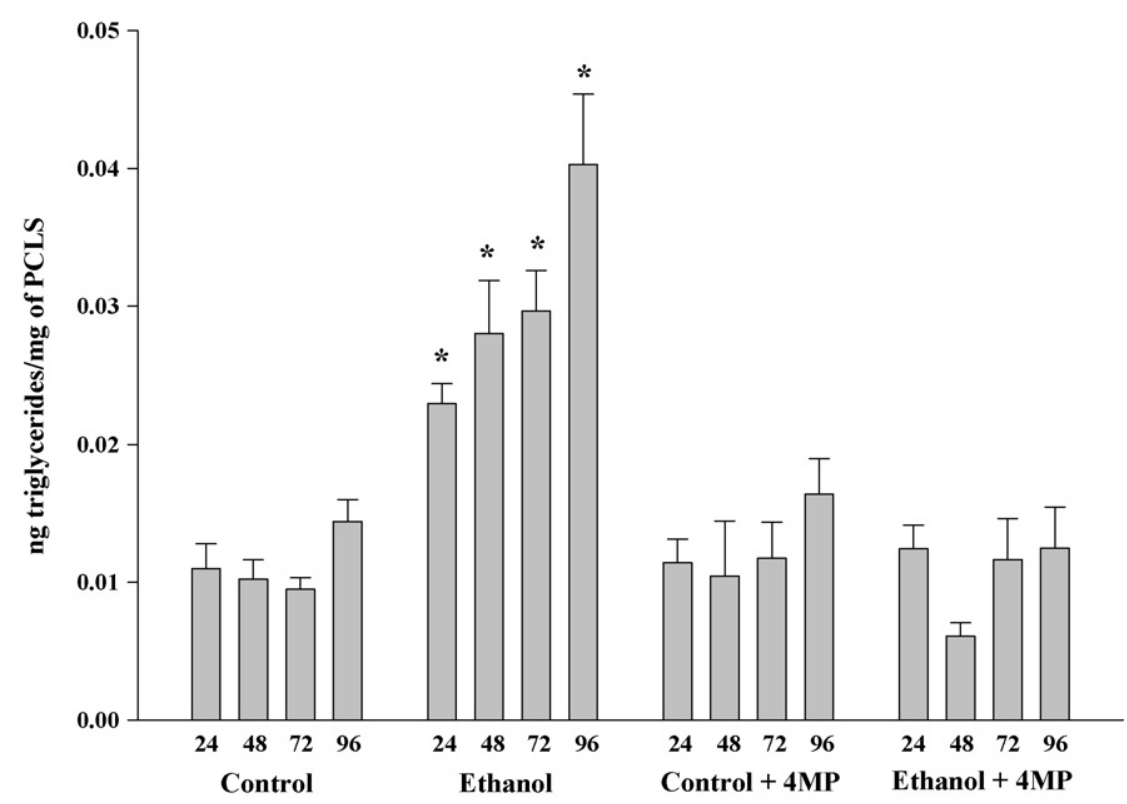

Fig. 7 - Triglyceride concentrations in rat precision-cut liver slices. PCLS were cultured at 24, 48, 72 and $96 \mathrm{~h}$ in the absence of ethanol (control), presence of $25 \mathrm{mM}$ ethanol (ethanol), absence of $25 \mathrm{mM}$ ethanol but in the presence of $0.50 \mathrm{mM} 4-\mathrm{MP}$ (control + 4-MP), and in the presence of both $25 \mathrm{mM}$ ethanol and $0.50 \mathrm{mM}$ 4-MP (ethanol + 4-MP). Data are expressed as the mean triglyceride levels $(\mu \mathrm{g})$ per $\mu \mathrm{g}$ of protein in the PCLS \pm S.E.M. of five separate experiments. Significantly increased for ethanol treated PCLS as compared to all other groups, ${ }^{*} \mathrm{P}<0.05$. 


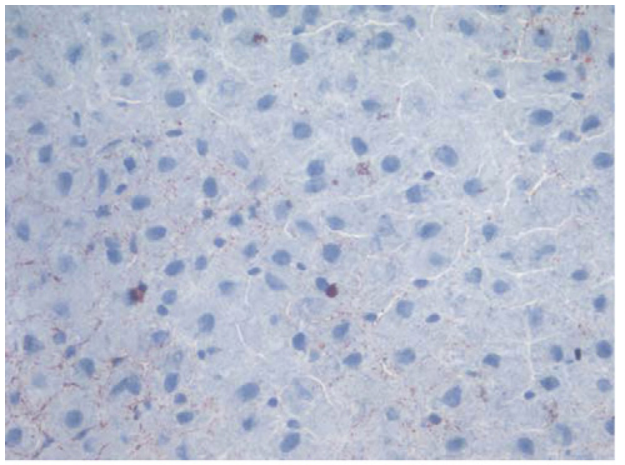

(A) Time 0 Slice

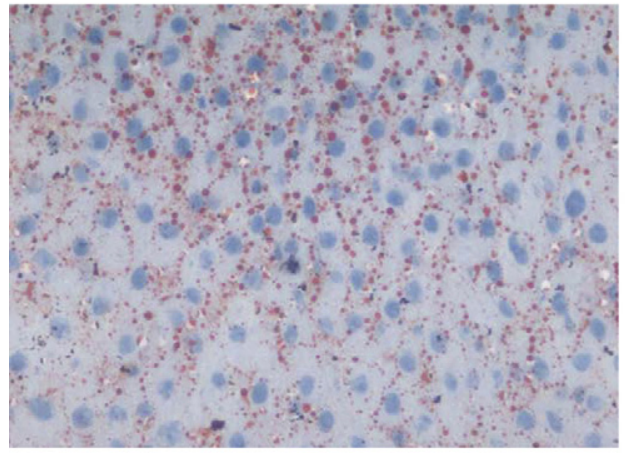

(C) Ethanol Slice 48 hour

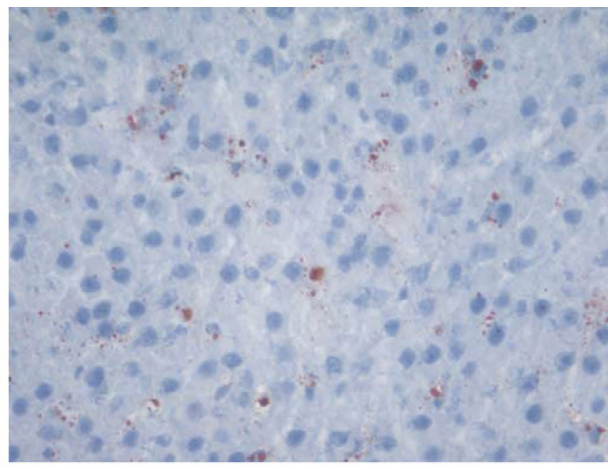

(B) Control Slice 48 hour

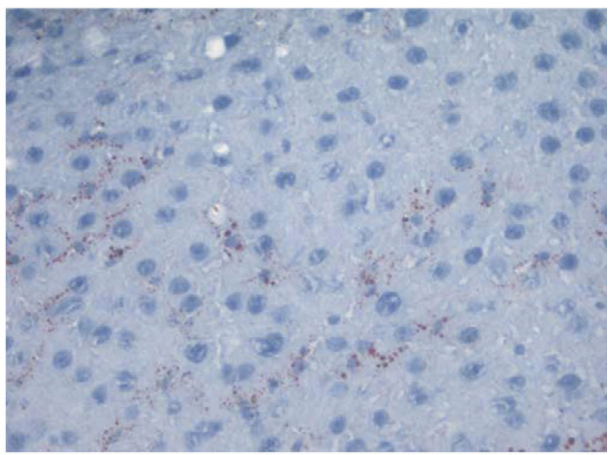

(D) Ethanol + 4MP Slice 48 hour

Fig. 8 - Oil Red $O$ staining of PCLS. PCLS were cultured for $t_{0}(A), 48 \mathrm{~h}$ in the absence of ethanol (B), $48 \mathrm{~h}$ in the presence of $25 \mathrm{mM}$ ethanol (C), and the presence of $25 \mathrm{mM}$ ethanol and $0.50 \mathrm{mM}$ 4-MP (D). Light microscopy photographs were taken at random on a Nikon Microphot-FXA microscope under $325 \times$ magnification. Photographs were taken using a Colorview II Olympus Camera and Software, and the figures are representative of six separate experiments.

fourfold elevation after $96 \mathrm{~h}$. Inhibition of ethanol metabolism with 4-MP essentially prevented all of these observed defects in tested hepatic functions, indicating a prominent role for ethanol metabolism via $\mathrm{ADH}$ in impaired hepatic function by ethanol.

In summary, PCLS have recently been used by other investigators studying the toxicological effects of a number of drugs and toxins $[10,13,32,34]$. It was the purpose of this study to determine whether PCLS could be used as a model system to study the effects of ethanol on the liver. In order to use this model it was first necessary to demonstrate that the PCLS could be cultured for an extended period of time without altering normal biochemical, functional and histological parameters. This has not been the case with liver slices in the past $[16,30]$. However, this model system has been altered from previous liver slice models by; ensuring the slices are uniformly very thin (200-300 $\mu \mathrm{m}$; approximately 8-10 hepatocytes thick), prepared and maintained under highly oxygenated conditions, and continuous changing of the media. These slices were viable, maintained their histological appearance, enzyme activities (ADH, ALDH, CYP2E1, etc.), and their function (albumin secretion) for up to $96 \mathrm{~h}$.

The addition of ethanol to these PCLS produced many of the same effects that have been observed in both isolated hepatocytes and in vivo models of chronic ethanol consumption $[1,2,9,40,41]$, including the oxidation of ethanol, acetaldehyde production, fatty liver, altered redox state, and the decreased secretion of albumin. All of these parameters were

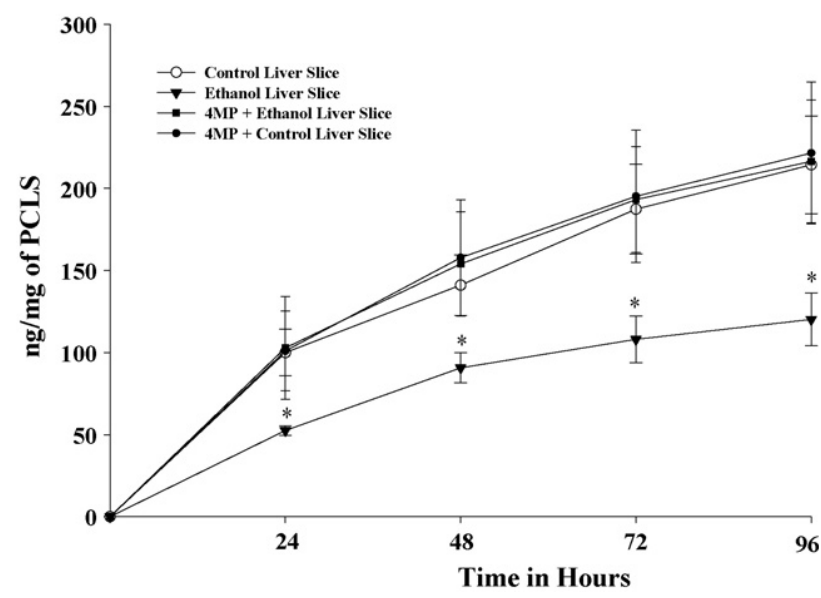

Fig. 9 - Albumin secretion by rat precision-cut liver slices. PCLS were cultured at 24, 48, 72 and $96 \mathrm{~h}$ in the absence of ethanol (control), presence of $25 \mathrm{mM}$ ethanol (ethanol), absence of $25 \mathrm{mM}$ ethanol but in the presence of $0.50 \mathrm{mM}$ 4-MP (control + 4-MP), and in the presence of both $25 \mathrm{mM}$ ethanol and 0.50 mM 4-MP (ethanol + 4-MP). Media were changed every $24 \mathrm{~h}$ and the levels of albumin determined for each time point. Data are expressed as the mean albumin levels (ng) per $\mu$ g of protein in the PCLS \pm S.E.M. of five separate experiments. Significantly decreased for ethanol treated PCLS as compared to all other groups, ${ }^{*} \mathrm{P}<0.05$. 
reversed in these studies by the addition of an inhibitor of ethanol metabolism (4-MP), which strongly suggests that this model has potential for studying the structural and functional consequences of ethanol-induced liver injury. Additionally, since all of the cell types are present during the incubation period in their appropriate conformation and matrix, this model should be very useful for studying the interactions of these cells types. Thus, it appears that these PCLS retain many of the biological functions that are lost when cells from the liver are isolated and cultured in vitro, and therefore, PCLS appear to be an attractive and useful model for the study of pathogenic mechanisms of alcoholic liver disease.

\section{Acknowledgements}

We thank the members of the Experimental Immunology Laboratory at the Omaha VA Medical Center including, Karen C. Easterling, Bartlett C. Hamilton III, and Kristin M. Lenczowski. This material is based upon work supported (or supported in part) by the Office of Research and Development Medical Research Service, Department of Veterans Affairs.

\section{R E F E R E N C E S}

[1] Levitsky J, Mailliard ME. Diagnosis and therapy of alcoholic liver disease. Semin Liver Dis 2004;24(3):233-47.

[2] Tsukamoto H, Lu SC. Current concepts in the pathogenesis of alcoholic liver injury. FASEB J 2001;15(8):1335-49.

[3] Pal-Bhadra M, Bhadra U, Jackson DE, Mamatha L, Park PH, Shukla SD. Distinct methylation patterns in histone $\mathrm{H} 3$ at Lys-4 and Lys-9 correlate with up- \& down-regulation of genes by ethanol in hepatocytes. Life Sci 2007;81(12):979-87.

[4] Lee YJ, Shukla SD. Histone H3 phosphorylation at serine 10 and serine 28 is mediated by p38 MAPK in rat hepatocytes exposed to ethanol and acetaldehyde. Eur J Pharmacol 2007;573(1-3):29-38.

[5] Clemens DL, Calisto LE, Sorrell MF, Tuma DJ. Ethanol metabolism results in a G2/M cell-cycle arrest in recombinant Hep G2 cells. Hepatology 2003;38(2):385-93.

[6] Clemens DL, Halgard CM, Miles RR, Sorrell MF, Tuma DJ. Establishment of a recombinant hepatic cell line stably expressing alcohol dehydrogenase. Arch Biochem Biophys 1995;321(2):311-8.

[7] Cederbaum AI, Wu D, Mari M, Bai J. CYP2E1-dependent toxicity and oxidative stress in HepG2 cells. Free Radic Biol Med 2001;31(12):1539-43.

[8] Kannarkat GT, Tuma DJ, Tuma PL. Microtubules are more stable and more highly acetylated in ethanol-treated hepatic cells. J Hepatol 2006;44(5):963-70.

[9] Schaffert CS, Todero SL, McVicker BL, Tuma PL, Sorrell MF, Tuma DJ. WIF-B cells as a model for alcohol-induced hepatocyte injury. Biochem Pharmacol 2004;67(11):2167-74.

[10] van de Bovenkamp M, Groothuis GM, Draaisma AL, Merema MT, Bezuijen JI, van Gils MJ, et al. Precision-cut liver slices as a new model to study toxicity-induced hepatic stellate cell activation in a physiologic milieu. Toxicol Sci 2005;85(1):632-8.

[11] Lerche-Langrand C, Toutain HJ. Precision-cut liver slices: characteristics and use for in vitro pharmaco-toxicology. Toxicology 2000;153(1-3):221-53.

[12] Guyot C, Combe C, Balabaud C, Bioulac-Sage P, Desmouliere A. Fibrogenic cell fate during fibrotic tissue remodelling observed in rat and human cultured liver slices. J Hepatol 2007;46(1):142-50.

[13] Olinga P, Hof IH, Merema MT, Smit M, de Jager MH, Swart PJ, et al. The applicability of rat and human liver slices to the study of mechanisms of hepatic drug uptake. J Pharmacol Toxicol Methods 2001;45(1):55-63.

[14] Olinga P, Groen K, Hof IH, De Kanter R, Koster HJ, Leeman WR, et al. Comparison of five incubation systems for rat liver slices using functional and viability parameters. J Pharmacol Toxicol Methods 1997;38(2):59-69.

[15] Fisher RL, Hasal SJ, Sanuik JT, Hasal KS, Gandolfi AJ, Brendel $\mathrm{K}$. Cold- and cryopreservation of dog liver and kidney slices. Cryobiology 1996;33(1):163-71.

[16] Tuma DJ, Zetterman RK, Sorrell MF. Inhibition of glycoprotein secretion by ethanol and acetaldehyde in rat liver slices. Biochem Pharmacol 1980;29(1):35-8.

[17] Crow KE, Cornell NW, Veech RL. The rate of ethanol metabolism in isolated rat hepatocytes. Alcohol Clin Exp Res 1977;1(1):43-50.

[18] Kamath SA, Narayan KA. Interaction of $\mathrm{Ca}^{2+}$ with endoplasmic reticulum of rat liver: a standardized procedure for the isolation of rat liver microsomes. Anal Biochem 1972;48(1):53-61.

[19] Omura T, Sato R. The carbon monoxide-binding pigment of liver microsomes. II. Solubilization, purification, and properties. J Biol Chem 1964;239:2379-85.

[20] Lowry OH, Rosebrough NJ, Farr AL, Randall RJ. Protein measurement with the Folin phenol reagent. J Biol Chem 1951;193(1):265-75.

[21] Wu D, Cederbaum AI. Expression of cytochrome P4502E1 in rat fetal hepatocyte culture. Mol Pharmacol 1996;49(5):802-7.

[22] Lieber CS. Metabolic effects of acetaldehyde. Biochem Soc Trans 1988;16(3):241-7.

[23] Sorrell MF, Tuma DJ. Hypothesis: alcoholic liver injury and the covalent binding of acetaldehyde. Alcohol Clin Exp Res 1985;9(4):306-9.

[24] Volentine GD, Ogden KA, Kortje DK, Tuma DJ, Sorrell MF. Role of acetaldehyde in the ethanol-induced impairment of hepatic glycoprotein secretion in the rat in vivo. Hepatology 1987;7(3):490-5.

[25] Hoek JB, Cahill A, Pastorino JG. Alcohol and mitochondria: a dysfunctional relationship. Gastroenterology 2002;122(7):2049-63.

[26] Galli A, Price D, Crabb D. High-level expression of rat class I alcohol dehydrogenase is sufficient for ethanol-induced fat accumulation in transduced HeLa cells. Hepatology 1999;29(4):1164-70.

[27] Clemens DL, Forman A, Jerrells TR, Sorrell MF, Tuma DJ. Relationship between acetaldehyde levels and cell survival in ethanol-metabolizing hepatoma cells. Hepatology 2002;35(5):1196-204.

[28] Corazzi L, Arienti G, Tirillini B, Porcellati G, Mezzasoma I, Orlando P. The effect of acute ethanol administration on phosphorylcholine uptake and metabolism in rat liver slices. Farmaco [Sci] 1979;34(7):612-20.

[29] Iritani N, Yamashita S, Numa S. Dietary control of triglyceride and phospholipid synthesis in rat liver slices. J Biochem 1976;80(2):217-22.

[30] Tuma DJ, Jennett RB, Sorrell MF. Impairment of glycoprotein secretion by phenobarbital in rat liver slices. Biochim Biophys Acta 1978;544(1):144-52.

[31] Sawyer JS, Daller JA, Brendel K, Yohem K, Putnam CW. The hepatotoxicities of endotoxin and ethanol comparisons in vitro using the precision-cut rat liver slice model. Life Sci 1994;55(18):1407-17.

[32] De Kanter R, De Jager MH, Draaisma AL, Jurva JU, Olinga P, Meijer DK, et al. Drug-metabolizing activity of human and rat liver, lung, kidney and intestine slices. Xenobiotica 2002;32(5):349-62. 
[33] Vickers AE, Saulnier M, Cruz E, Merema MT, Rose K, Bentley $\mathrm{P}$, et al. Organ slice viability extended for pathway characterization: an in vitro model to investigate fibrosis. Toxicol Sci 2004;82(2):534-44.

[34] Vickers AE, Fisher RL. Precision-cut organ slices to investigate target organ injury. Expert Opin Drug Metab Toxicol 2005;1(4):687-99.

[35] Dogterom P. Development of a simple incubation system for metabolism studies with precision-cut liver slices. Drug Metab Dispos 1993;21(4):699-704.

[36] Behrsing HP, Vickers AE, Tyson CA. Extended rat liver slice survival and stability monitored using clinical biomarkers. Biochem Biophys Res Commun 2003;312(1):209-13.
[37] Nuutinen HU, Salaspuro MP, Valle M, Lindros KO. Blood acetaldehyde concentration gradient between hepatic and antecubital venous blood in ethanol-intoxicated alcoholics and controls. Eur J Clin Invest 1984;14(4): 306-11.

[38] Eriksson CJ. Acetaldehyde metabolism in vivo during ethanol oxidation. Adv Exp Med Biol 1977;85A:319-41.

[39] Dey A, Cederbaum AI. Alcohol and oxidative liver injury. Hepatology 2006;43(2 Suppl 1):S63-74.

[40] Tuma DJ, Sorrell MF. Effects of ethanol on protein trafficking in the liver. Semin Liver Dis 1988;8(1):69-80.

[41] Lieber CS. Medical disorders of alcoholism. N Engl J Med 1995;333(16):1058-65. 